\title{
aniki
}

Revista Portuguesa da Imagem em Movimento Portuguese Journal of the Moving Image

\section{O universo de coisas de Apichatpong Weerasethakul: A fenomenologia para além da relação entre o humano e o mundo Julio Bezerra ${ }^{1}$}

\section{Introdução}

Uma sala de cinema. Alguns, poucos, espectadores. Deduzimos que entre eles estão Itt e Jen, nossos protagonistas. É possível ver apenas a parte de trás de suas cabeças e a tela à frente. O trailer de um "picante" filme de terror sobrenatural está sendo exibido. Quando termina, o público fica de pé para o hino nacional tailandês, o que antecede a atração principal - como é exigido por lei. No entanto, em vez de música, só há silêncio. Experimentamos em seguida uma montagem em tableaux. A imagem em contre-plongée de um ventilador de teto que vibra cores, azul, roxo e vermelho. Nós o ouvimos. Seu barulho cria um ritmo sereno; uma espécie de constante estado de tranquilidade é construído e irá perdurar por todo o filme. Corte. Vemos agora dois planos de pessoas dormindo no que parece ser a enfermaria de um humilde hospital. Há postes ao lado de suas camas. Eles mudam de cor e seu brilho ilumina o quadro. A floresta está lá fora, através das janelas. Está escuro. Corte. Um poste de luz nos permite ver um grupo de pessoas desabrigadas, dormindo ao lado de um mural de Sarit Thanarat (um soldado que comandou um golpe em 1957 e manteve-se primeiro-ministro até morrer em 1963). Corte. Um plano longo e aberto de um parque em toda sua profundidade de campo. Um reservatório ocupa o centro do quadro. Do lado esquerdo, um homem recolhe o lixo. Um casal está sentado, conversando. As pessoas andam em torno do quadro, a uma certa distância. Corte. Um homem dorme em um ponto de ônibus com um anúncio do "Estúdio de casamento da UE" ao fundo. Bicicletas e carros passam. Corte. Ao voltarmos ao shopping e seus néons, um Itt inconsciente está sendo carregado para fora da sala de cinema, através de um labirinto de escadas rolantes. Nós o acompanhamos até ele deixar o quadro. Um longo fade nos leva novamente à enfermaria, onde um grupo de homens dormem, banhados pelo brilho sinistro de suas máquinas de sonho.

Esta é uma das sequências mais elogiadas de Cemitério do esplendor (Rak ti Khon Kaen, 2015), dirigido pelo cineasta tailandês Apichatpong Weerasethakul. Após mais de uma década depurando,

\footnotetext{
${ }^{1}$ Universidade Federal do Rio de Janeiro, Escola de Comunicação, CEP 22290-240, Rio de Janeiro, Brasil.
} 
relendo e procurando maneiras novas e sutis para afirmar seus princípios e mecanismos estéticos, narrativos e discursivos, sempre permanecendo fiel aos seus temas e estilo, Apichatpong, um dos cineastas mais criativos e originais do cinema contemporâneo, lança seu novo filme com a mesma frescura de sempre. Ele instala o espectador em um estado constante de admiração perante o mundo, elevando a aparente simplicidade da sua encenação naturalista a camadas de significado complexo e uma abertura para os mistérios da existência. Há um paralelismo constante entre o naturalismo das cenas e um todo espiritual, mágico, metafísico, algo onipresente em todas as suas obras, que contamina cada quadro e se projeta dentro e para além da matéria fílmica.

A crença de que a fenomenologia nos faz imaginar uma forma mais adequada para atender a demanda diversificada que um certo cinema contemporâneo nos impõe é o nervo central de minhas pesquisas mais recentes. A fenomenologia (seja a filosofia de Maurice Merleau-Ponty ou dos teóricos que foram inspirados pela fenomenologia, como André Bazin) procura no cinema um reencontro com um contato mais ingênuo entre formas, cores, planos, o movimento e o que eles expressam, desconstruindo essas várias camadas de significado e reconstruindo-as no próprio filme, em seu fluxo e refluxo. É por isso que, em face de um filme como o Cemitério do esplendor, poderemos encontrar na fenomenologia várias ferramentas exploratórias, um esboço metodológico ou, pelo menos, um frutífero interlocutor.

No entanto, há algo diferente, muito particular, quando se trata de Apichatpong Weerasethakul. Ele parece se recusar a fazer qualquer distinção entre sujeito e objeto, e filma o mundo em um tempo antes da separação e diferenciação organizacional de seus seres. Ele não identifica o "ser" com um dos seres (Deus, o homem ou a natureza) e rejeita um modo de pensar com base nessa clivagem. Olhares, personagens, o suor escorrendo por seus corpos, pedras, animais, floresta, o sol e sua luz... Tudo é descrito no mesmo nível, na mesma hierarquia narrativa. Uma narrativa física que enfatiza a unidade de todas as coisas, uma espécie de cosmos. Não é a natureza ou os objetos que são humanizados, mas o próprio homem que perde sua humanidade. O homem é parte de algo maior do que a humanidade.

A fenomenologia precisa de ajuda quando vamos para além da questão do ser humano e do mundo. E é justamente esse caminho que pretendo percorrer. Para responder aos mistérios de Apichatpong Weerasethakul, temos de ir ainda mais longe na descentralização da humanidade. Temos de entrar em territórios não-humanos. Devemos dar a todos os objetos e suas interações a mesma atenção. Pois, se não é possível saber o que é ser uma coisa não-humana, um filme como Cemitério do esplendor parece mostrarnos que é possível reunir certo conhecimento metafísico para além 
do humano sem acessá-lo diretamente. Este é o nosso propósito: uma análise objeto-orientada, que traça as suas raízes na fenomenologia e se envolve em um diálogo com Alfred North Whitehead e o realismo especulativo. A exploração da prática de Apichatpong Weerasethakul dentro deste quadro pode levar-nos a um ponto de partida diferente para a teoria do cinema, enfatizando sua aposta ontológica.

\section{Apichatpong Weerasethakul}

De Objeto misterioso ao meio-dia (Dokfa nai meuman, 2000) a Cemitério do esplendor (2015), Apichatpong Weerasethakul faz filmes como se estivesse intuindo um tom ou um estado de espírito. Ele é geralmente creditado não pelo tradicional "dirigido por", mas pelo um pouco pretensioso "concebido por". É, certamente, uma descrição estranha, porém absolutamente justificada. Embora seus filmes sejam experiências conceituais muito rigorosas, há uma sensualidade que emana de cada um dos seus planos, um sentimento quase religioso de revelação. É o que Tony Ryans descreve de forma sucinta:

É difícil escrever sobre os filmes de Apichatpong sem depender do vocabulário da dúvida: "aparente", "aparentemente", "enigma”, "opaco", e assim por diante. Há certamente algo evasivo no coração da obra de Apichatpong, algo para além da relutância modernista de se comprometer com significados e significantes rasos e banais. Mas há também um compromisso sério com a tradição surrealista, a crença na ideia de que justaposições irracionais podem produzir insights inesperados; sem falar no interesse de Apichatpong pelo pensamento budista - mais especialmente pela busca pelo "vazio" como passo essencial para a iluminação: a rejeição barthesiana da noção de "autoria" encontra a abnegação budista da ideia de sujeito. (Ryans 2009, 138-139)

Quando um filme de Apichatpong Weerasethakul começa, só vemos seus créditos de abertura passada mais de meia hora de duração, como em Eternamente sua (Sud sanaeha, 2002). Suas histórias podem tanto repetir-se interminavelmente (Objeto misterioso ao meio-dia) ou começar de novo, de súbito, com personagens e cenários ligeiramente alterados (Mal dos trópicos/Sud pralad, 2004, e Síndromes e um século/Sang sattawat, 2006). Apichatpong Weerasethakul tende sempre ao mundo natural (especialmente à floresta) quando se trata de paisagem e cenário, e ao êxtase quando se trata da atmosfera de um filme. O cineasta parece apostar em um curioso abandono do racionalismo, como bem afirma James Quandt (2009, 14): "os filmes de Apichatpong estão entre os mais sensuais, suaves e desconcertantes longas do cinema contemporâneo”.

Apichatpong Weerasethakul dilata o presente em uma sucessão de acontecimentos e sensações simultâneas, colocando seus personagens e os espectadores em um estado de perplexidade diante 
do mundo. Ele transforma os objetos e paisagens mais comuns em imagens inefáveis e enigmáticas, em regiões espectrais onde tudo é transitório e mutante, onde mídias, textos, mitos, máquinas, objetos, histórias e rituais vivem em igualdade, onde as histórias se metamorfoseiam, mudam de direção, ou começam de novo, do fato à ficção, da fantasia ao documentário. Em uma entrevista para uma revista brasileira, o cineasta diz:

Viver, respirar, é uma alegria. E nisso eu acredito. Eu tento que meu trabalho reflita a forma como eu vivo e sinto a vida, ou seja: a forma de meu prazer se relacionar com as imagens. Nem sempre é possível porque o cinema não é a vida, e é cheio de pequenas complexidades técnicas. É por isso que de alguma forma eu quero que meus filmes reflitam ao menos a "alegria de poder filmar e de estar filmando", como que em um olhar reverso para dentro dos filmes. É uma forma de combinar e colocar em diálogo a minha vida sem filmes e a minha vida enquanto eu filmo. É o mais próximo que eu posso chegar da verdade. Uma interação dupla entre essas minhas duas formas de estar vivo, esse duplo. (Bragança 2006)

Consideremos o seu filme mais recente, Cemitério do esplendor - seu título original em tailandês significa literalmente "Amor em Khon Kaen”, referindo-se à locação do filme, cidade natal do diretor no norte da Tailândia. O longa é inspirado em um incidente real e envolve a enfermaria de um hospital ainda em construção e cheio de soldados acometidos por uma misteriosa doença do sono. Sua protagonista é uma mulher local de meia-idade Jen (Jenjira Pongpas). Ela visita a enfermaria como voluntária e o hospital está sendo construído no local de sua antiga escola primária. Andar por ali é para ela como voltar atrás no tempo, quando as coisas eram menos complicadas e mais felizes. Na enfermaria, ela se aproxima de um dos soldados doentes, chamado Itt (Banlop Lomnoi) e de uma jovem de nome Keng (Jarinpattra Rueangram), cujos supostos poderes psíquicos chegaram a atrair a atenção do FBI. Um método incomum de tratamento está sendo testado nos soldados. Postes luminosos são instalados ao lado de suas camas para acalmar suas mentes perturbadas - em determinado momento, aprendemos que a inusitada técnica surgiu de um estudo neurológico realizado no MIT que criou com sucesso memórias artificiais em ratos, expondo seus neurônios a flashes de luz. Estes postes estão constantemente mudando de cor, influenciando o humor na ala, enquanto todas as janelas estão fechadas, bloqueando a visão do mundo exterior. Quando os postes brilham e os soldados se mostram envoltos em escuridão e cores, é como se estivéssemos olhando para um estranho pedaço de instalação artística ou talvez uma curiosa inversão da parábola da caverna de Platão.

À medida que o filme avança, aprendemos que há uma razão para a doença. O hospital foi construído no local de um antigo palácio onde reis foram enterrados há milhares de anos. Em outro mundo, esses reis ainda estão em guerra, drenando as energias dos 
soldados. Tudo indica que eles nunca vão acordar - e esta impressão vem embalada em uma sensação um tanto pessimista, salientando o estado de uma nação que tem sido governada por uma junta militar desde que um golpe de Estado, em maio de 2014, tomou o país. Apenas uma certa face desta realidade é visível na superfície de um filme que parece suave e sereno. Cemitério do esplendor expressa, em seguida, a história de dois mundos, um visível e um invisível, ambos existindo em simultâneo. Apichatpong Weerasethakul cria, com muita simplicidade, um universo onde humanos e não-humanos, "sonho e realidade, passado e presente, se misturam constantemente, mas que é sempre baseado (o universo) em um palpável agora” (Koresky 2016).

Cemitério do esplendor sempre parece estar à beira de um tipo de explosão epifânica. Uma certa forma de hipnose nos está sendo oferecida. Há uma lógica curiosa de diluição narrativa. O caso de amor de Itt e Jen se espalha por toda a paisagem, pelos seus corpos e por tudo o que os cerca. Uma imagem não está mais subordinada ao drama, à organização dramática e ou plástica dos elementos de um filme, nem a um discurso ou ideologia específica. Em vez de estabelecer um contexto de informações, o que nos daria os elementos necessários para nos orientarmos no meio de uma história, Apichatpong Weerasethakul se concentra em certas qualidades fundamentais do cinema, que tendem a ser anuladas por suas funções representativas, discursivas e narrativas: as variações de movimento e luz, cores e sons, um processo de figuração constante e de constituição de atmosferas, tons e ritmos.

Apichatpong Weerasethakul é um panteísta. Seus filmes não são uma forma de diluir a experiência, mas de saboreá-la e expandila ao infinito. Cemitério do esplendor não é feito em um movimento de antagonismo em relação aos estilos mais convencionais (sejam eles "artísticos" ou "comerciais"). Muito pelo contrário. Não existe nada no sentido de uma "incompatibilidade irredutível" quando se trata desse filme. Em um ponto, vemos pessoas caminhando ao redor do lago. Elas se sentam e se levantam. Trocam de posições entre si. Uma cena meticulosamente encenada, coreografada, e aparentemente gratuita. Em outro momento, de forma absolutamente inesperada, testemunhamos uma imagem CGI de uma ameba flutuante em um céu azul brilhante. Apichatpong Weerasethakul encontra o extraordinário no ordinário. Ele é um contador de histórias compulsivo, embora a sensação na maioria das vezes seja a de que nenhuma história está realmente nos sendo contada. Ele pode ser engraçado e trágico. Cemitério do esplendor é um melodrama e um filme espiritual. É uma experiência conceitual e sensorial. O realismo é árido e mágico, ao mesmo tempo. É político sem ser exatamente militante.

Cemitério do esplendor é de uma serenidade esmagadora e inteiramente desinteressada na interrupção ou no choque, mas, ao 
mesmo tempo, movido por um sentimento inconfundível de urgência social. O filme talvez pareça se dar em um real fora do tempo; no entanto, é também uma obra do presente em seus mínimos detalhes. Kong Rithdee descreve brilhantemente a tensão subversiva entre tranquilidade e ansiedade que existe sob as aparências calmas do cinema de Apichatpong Weerasethakul:

Em meio às lembranças enigmáticas e à beleza verdadeira, Cemitério de esplendor é o primeiro filme tailandês que responde às incertezas política, pessoal, histórica - de uma Tailândia sob regime militar. É ainda mais surpreendente que esta profecia negra seja feita do jeito mais suave e civilizado, porém sagaz e inflexível (Rithdee 2015, 48).

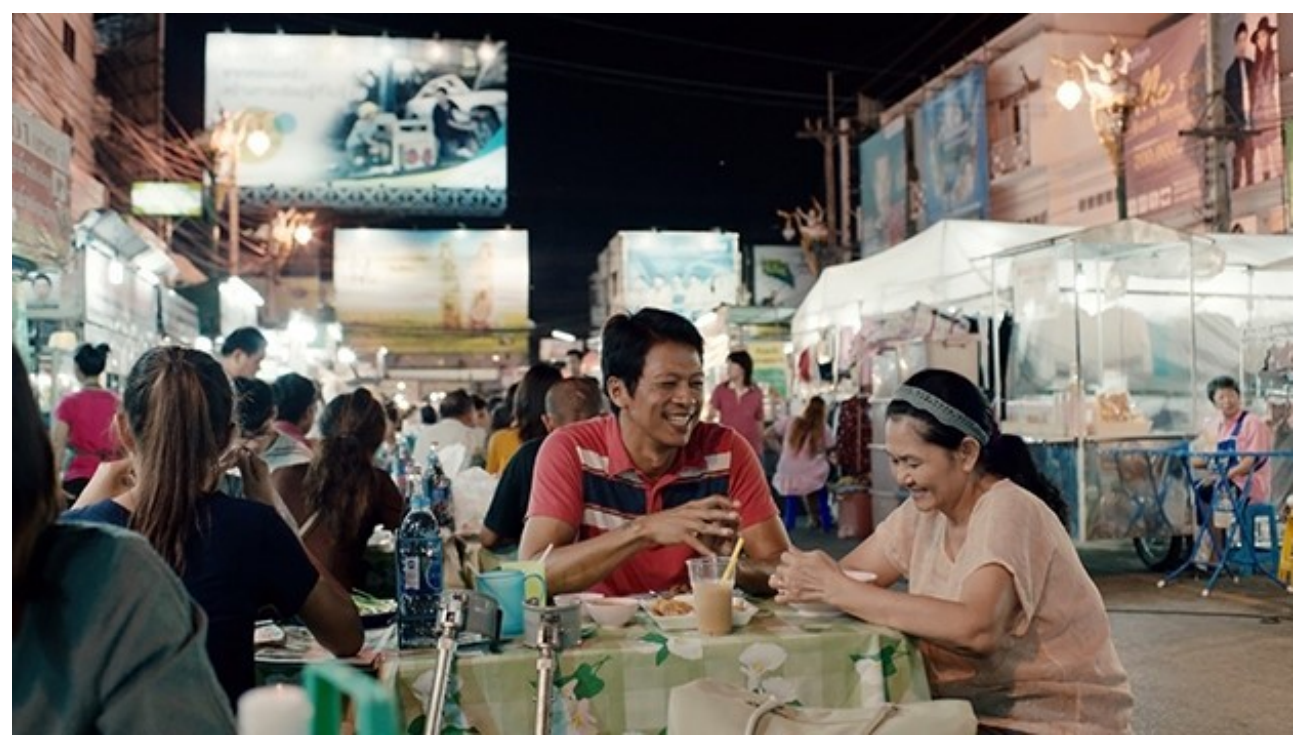

Imagem 1: Cemitério do esplendor (Apichatpong Weerasethakul, 2015) (C) Kick the Machine

Cemitério do esplendor é feito de planos abertos (Apichatpong Weerasethakul sempre evita close-ups), longos e estáticos, que nos permitem ver os personagens inseridos no espaço do quadro, sofrendo a influência de outras ações, objetos e personagens. Tudo importa. A própria presença de elementos imóveis, objetos, plantas, lagos, terra, grama e edifícios, contextualiza de forma mais ampla a presença reduzida dos personagens na grandeza do mundo. Podemos voltar à sequência descrita anteriormente, em que os personagens, paisagens e vários objetos parecem absolutamente interligados. Estes planos, desconectados mas sensual e visualmente coerentes, estão todos trabalhando em um sentido de suspensão do tempo, sob uma atmosfera de compaixão. É como uma flutuação, uma inundação etérea de ações e objetos. Compreender ou representar um objeto é menos importante do que ficar perdido em uma espécie de intoxicação estética. Encontramo-nos inebriados pelos objetos do mundo: objetos que estão além de qualquer possibilidade de presença total, mas enraizados em um ambiente carnal onde nossos 
corpos se encontram com as texturas voluptuosas de todas as coisas. Apichatpong Weerasethakul quer nos colocar antes de todo o raciocínio, no mesmo plano da realidade, no nível das "coisas mesmas". É como se o famoso lema da fenomenologia - "voltar às coisas mesmas" - também estivesse em sua agenda.

\section{Fenomenologia, idealismo e correlacionismo}

A fenomenologia se perpetua como corrente filosófica que visa esclarecer de que maneira a possibilidade de conhecer eventos e objetos mundanos se funda nas estruturas da consciência. É uma investigação centrada no conceito de "intencionalidade". Oriundo de Brentano, de quem Husserl foi aluno, o conceito de intencionalidade sugere que a característica essencial da consciência é a sua qualidade de se referir sempre a algo que não ela mesma: ter consciência é sempre ter consciência de alguma coisa. Em outras palavras, a consciência é uma atividade constituída por atos (perceção, imaginação, especulação, volição, paixão, etc.), com os se quais visa algo. Para Husserl, como para Brentano, os fenômenos mentais ou subjetivos são intencionais. A perceção é perceção de um percebido, o desejo é desejo de um desejado, a imaginação é imaginação de um objeto imaginado... Não há distinção entre o papel atuante do sujeito que conhece e a influência do objeto conhecido. O que não quer dizer que o objeto esteja contido na consciência, mas que só tem seu sentido de objeto para uma consciência, que sua essência é sempre o termo de uma visada de significação. A consciência só é consciência estando dirigida para um objeto, assim como o objeto só pode ser definido em sua relação com a consciência.

Husserl caracterizou a fenomenologia como "uma volta às coisas mesmas”. É, contudo, preciso ter cuidado. Husserl não se refere a um retorno às coisas no mundo objetivo. Ele quer dizer, em vez disso, um retorno às coisas tais como elas são ou parecem ser em nossa experiência "original” delas, antes de adquirirem as características que tão cegamente pressupomos que elas tenham. Husserl queria identificar o que era essencial na experiência do mundo a partir do ato da perceção. Pensar sempre foi pensar "sobre algo", mas o seu conteúdo poderia ser concebido, ele insiste, como dados em si, sem referência ao mundo natural dos objetos "lá fora". O mundo fenomenológico é composto dos modos de doação dos objetos em correlação com os atos da consciência. Para Husserl, o meu medo de voar não pode ser descrito como um conjunto natural de átomos e químicas, códigos genéticos e localizações geométricas. Antes de explicar os elementos do mundo por meio de qualquer teoria, devemos nos concentrar diligentemente sobre a única coisa que é realmente dada: a experiência como tal. O que sinto é um medo paralisante, não o movimento de mecanismos químicos através dos meus nervos. O que ouço são ruídos do avião e os passageiros, não as 
ondas sonoras que viajam através do espaço e fazem meu tímpano vibrar. Somos convidados a suspender a crença em quaisquer causas ocultas ou poderes secretos, para nos determos apenas no que imediatamente se mostra. Somos convidados, em outras palavras, a deixar que os fenômenos falem por si.

Ou seja: a fenomenologia recomenda um passo para trás na direção do mundo como ele aparece, antes do emprego de quaisquer teorias. Seu ponto de partida é justamente pôr entre parênteses todas as teorias do mundo natural e se concentrar em uma descrição de como as coisas aparecem na arena fenomenal. A fenomenologia marca um status fenomenal para os seres, do qual eles nunca conseguirão escapar. Isso dá à luz um problema filosófico fundamental: "quando a fenomenologia substitui objetos naturais por fenômenos", insiste Graham Harman, "devemos perguntar se, dessa forma, ela não reduz o mundo à aparência, colocando-a entre parênteses, tornando inexistente toda e qualquer realidade mais profunda" (2011, 10). Para Husserl, qualquer noção de coisas em si para além do alcance da intencionalidade é tratada como absurdo. O idealismo de Husserl é, portanto, evidente. A crença de que estamos sempre já fora de nós, intencionando objetos, não é suficiente. Isso não muda o fato de que, para Husserl intencionalidade significa objetividade imanente - a objetividade sendo considerada dentro do âmbito da experiência, em vez de transcendendo-a. Husserl afirma ainda que não faz sentido imaginar algo que pode não ser o correlato de um ato intencional.

O que é curioso é que Husserl, apesar de tudo, parece realista. Esta impressão vale também para fenomenologia em geral. Porquê? Talvez tenha algo a ver com o fato de "o idealismo husserliano não deixar de ser orientado aos objetos em seu núcleo" (Harman 2011, 43). Embora os objetos intencionais da fenomenologia não existam fora da experiência e, portanto, não sejam o terreno da experiência, os objetos da fenomenologia são o território para as aparências dos objetos. A visão empirista do conteúdo mental que sempre o tratou como composto de qualidades distintas embaladas em um pacote, como se um objeto não fosse nada mais do que todo o seu conteúdo combinado, é revista. O mundo é feito de coisas incontáveis. Estamos sempre imersos e rodeados por inúmeros objetos em um dado momento: animais, construções, plantas, montanhas, frutas, etc. Vemos esses objetos de uma forma muito concreta e sempre de acordo com um determinado ângulo e distância e sob condições específicas de iluminação. Tudo o que emerge da minha experiência destes objetos pertence ao conteúdo da minha experiência. No entanto, cada experiência é mais do que o seu conteúdo explícito. Nós podemos tomar o exemplo de uma planta. Posso regá-la, agarrá-la, jogá-la fora, e, enquanto faço cada uma dessas ações, o conteúdo da minha experiência muda, mesmo que eu esteja experimentando a mesma planta. Um objeto intencional não é um conjunto de qualidades. Ele é, na 
verdade, o contrário: "as qualidades que experimentamos são sempre qualidades do objeto" (Harman 2013, 44).

Husserl é um idealista, mas suas obras são recheadas com as texturas carnais e densas dos objetos. Esta faceta de Husserl é levada ainda mais longe por sucessores talentosos, especialmente Maurice Merleau-Ponty, para o qual as entidades são tão carnais e enigmáticas que nos sentimos invariavelmente para além do idealismo. Há algo novo e excitante sobre suas descrições. Merleau-Ponty chama "a cidade cujo temperamento reconheço na atitude de um policial ou no estilo de um edifício público" $(1994,27)$. Ele chama a atenção para "um cinzeiro ou um violino" (Merleau-Ponty 1994, 264). Fala sobre experiências com narcóticos, sobre mágicos (Merleau-Ponty 1994, 315), casas mal-assombradas (Merleau-Ponty 1994, 315) e meteoritos (Merleau-Ponty 1994, 312). Em o Visível e o invisível, conclui: "Como o cristal, o metal e muitas outras substâncias, sou um ser sonoro, mas a minha vibração, essa é de dentro que a ouço; como disse Malraux, ouço-me com minha garganta" (Merleau-Ponty 2000, 140). Obcecado com as cores mais escuras,

[c]omo o negrume secreto do leite, de que falou Valéry, só é acessível por meio da sua brancura, a idéia da Luz ou a idéia musical revestem por baixo as luzes e os sons, formando o outro lado ou a profundidade deles. Sua textura carnal se nos apresenta como ausente de toda carne, e um sulco que se traça magicamente sob nossos olhos sem que ninguém o traçasse, certo oco, certo interior, certa ausência, uma negatividade que não é um nada, estando limitada precisamente a estas cinco notas entre as quais se instala, a esta família de sensíveis que chamamos luzes. Não vemos nem ouvimos as idéias, nem mesmo com os olhos do espírito ou com o terceiro ouvido: no entanto, ali estão, atrás dos sons ou entre eles, atrás das luzes ou entre elas, reconhecíveis na sua maneira sempre especial, única, de entrincheirar-se atrás deles, perfeitamente distintas umas das outras, desiguais entre si no valor e significação. (MerleauPonty 2000, 145-146)

No entanto, é preciso ouvir a provocação incisiva de Harman (2011, 10): quando se trata de Merleau-Ponty, é possível falar de uma camada do mundo que escapa à aparência, ou isso é apenas uma recaída no tipo de teoria contra a qual a fenomenologia deve sempre se opor? Será que o mundo que Merleau-Ponty tão lindamente descreve tem uma realidade autônoma fora da nossa perceção?

Acredito que sim. Já no prefácio de Fenomenologia da Percepção, Merleau-Ponty mostra um sentido apurado para a resistência inata do mundo: "O real é um tecido sólido, ele não espera nossos juízos para anexar a si os fenômenos mais aberrantes, nem para rejeitar nossas imaginações mais verossímeis" (1994, XI). Em outras palavras, as essências de que fala a fenomenologia não são apenas "significados" para a consciência humana. São realidades. Embora o nosso encontro com as coisas pareça apenas iluminá-las, na medida em que elas são importantes para nós, isso apenas prova, de acordo 
com Merleau-Ponty, que não estamos atentos o suficiente para "o elemento não-humano que se encontra escondido nel[a]s" (1994, 375). Como ele mesmo diz: "viver uma coisa não é nem coincidir com ela nem pensá-la de uma parte à outra" (Merleau-Ponty 1994, 380).

No final de sua vida, Merleau-Ponty deu mais um passo, quando compreendeu não ter conseguido em suas duas primeiras obras se desprender completamente do ponto de vista da filosofia transcendental que concebe a primazia da consciência em face de seu objeto. Por ocasião da sua morte, o fenomenólogo trabalhava em uma obra que permaneceria inacabada. O visível e o invisível, da qual apenas a primeira parte e algumas notas se encontravam redigidas, testemunha um esforço para dar uma nova expressão ao seu pensamento. Se em Fenomenologia da percepção, a análise do fenômeno percetivo permitia a Merleau-Ponty descrever a experiência, assinalando o acoplamento entre sujeito e objeto, entre o corpo e o mundo, partindo da dualidade entre estes polos para reconciliá-los na unidade do campo experiencial, em $\mathrm{O}$ visível e o invisível a experiência é descrita como deiscência. Pensar nossa relação com o ser como deiscência é não mais concebê-la como acoplamento, fusão ou coincidência, mas como fissão que, a partir da unidade primordial da carne, faz surgir, um para o outro, corpo e mundo, observador e observado, eu e outro.

É bem sabido que a noção de "carne" é o nervo central das reflexões posteriores de Merleau-Ponty, que a forja e utiliza a fim de ilustrar um tipo de ser que "não tem nome na filosofia" $(2000,147)$, em uma tentativa de evitar qualquer referência seja a um sujeito ou a um objeto. Não é nem matéria, nem mente, nem substância. Pelo contrário, é a textura unitária, na qual cada organismo e coisa se manifestam apenas como diferença em relação a outros órgãos e outras coisas. A carne reúne atividade e passividade. Ela designa o horizonte comum ao qual todos os seres pertencem. Para Merleau-Ponty, "carne" não se refere a uma origem, mas a algo "originário", que, adverte, "não é tudo o que está atrás de nós" (2000, 124), mas sim "uma única explosão de Ser que é para sempre" (2000, 265). É neste sentido que Merleau-Ponty afirma a interpenetração do consciente e do sensível e o parentesco entre o nosso corpo, o corpo do outro, e as coisas do mundo, que os envolve em um horizonte de ser "bruto" ou "selvagem".

No final de sua vida, o filósofo francês nos deu instrumentos suficientes para ir além do "idealismo orientado aos objetos" de Husserl. Ele diz que quando olho para o mundo, o mundo olha para mim. Para Merleau-Ponty, o real não pode ser reduzido ao que parece real para a consciência humana, como alguém como Tom Sparrow (2004) o acusa de dizer. No entanto, é verdade que o ser humano permanece sempre parte da equação quando se trata de Merleau-Ponty. O correlato mundo-humano ainda está no centro de 
sua filosofia. Não é que Merleau-Ponty acredite que não há relação real entre cadeiras, chaminés, e relógios quando os humanos não estão em cena; ele apenas não prestou atenção suficiente a essas realidades.

Ou seja: se Husserl é um idealista, Merleau-Ponty poderia muito bem ser descrito como um correlacionista. O termo foi criado por Quentin Meillassoux, à beira do que viria a ser conhecido como realismo especulativo, para descrever o tipo de filosofia que fundamenta todo o pensamento sobre a interação mútua do ser humano e do mundo. É a doutrina segundo a qual "nós nunca agarramos um objeto em si, isolado de sua relação com um sujeito" (Meillassoux 2008, 5). De acordo com o correlacionismo, "tudo se reduz a uma questão de acesso humano ao mundo, e as relações não-humanas são abandonados às ciências naturais" (Harman 2009, 156). Em outras palavras, como nos diz Harman:

o correlacionista sustenta que não podemos pensar em seres humanos sem mundo, nem mundo sem seres humanos, mas apenas em um relacionamento primal ou correlação entre os dois. Para o correlacionista, é impossível falar de um mundo que pré-exista aos humanos. (Harman 2009, 122)

É como se o que está fora do pensamento tivesse de permanecer para sempre impensável - como Harman (2010, 789) sarcasticamente resume. Apichatpong Weerasethakul, pelo contrário, não pode ser considerado um correlacionista. Seus filmes parecem ser explorações do que significa pensar sobre a realidade, sem colocar preocupações sobre a capacidade do ser humano de conhecer o mundo no centro de toda a discussão. Ele descreve um mundo povoado não por sujeitos ativos e objetos passivos, mas por materiais animados e interativos, essencialmente, por corpos humanos e não-humanos. Apichatpong Weerasethakul parece dedicado ao que Salvador Dalí $(1998,80)$ chamou de "a autonomia poética das coisas". Os objetos não são importantes por causa de seu efeito sobre o sujeito humano, mas em si mesmos. Se Merleau-Ponty provoca a aniquilação mútua entre sujeito e objeto, e a libertação do êxtase de toda razão, a abordagem de Apichatpong Weerasethakul insiste na persistência ontológica das coisas fora da subjetividade humana, mediante uma liberdade de todas as coisas, sem distinção entre o humano e o não-humano.

Em um filme como Cemitério do esplendor, estou constantemente sendo forçado a reconhecer a integridade das coisas, totalmente à parte de mim. Estes encontros alteram os parâmetros do mundo, destruindo "a tessitura de significado" e rompendo com todos os consensos. Cemitério do esplendor faz ontologia. Em uma sequência como a descrita no início deste artigo, podemos encontrar a justaposição de seres humanos, máquinas, natureza, cores, a escuridão da noite, narrativa, conceitos, etc. Apichatpong Weerasethakul 
não identifica o ser com um dos seres e rejeita um modo de pensar com base nessa clivagem.

\section{Alfred North Whitehead}

É justamente aqui que Alfred North Whitehead se torna um grande interlocutor. Ele tem um lugar importante na genealogia do que chamamos de realismo especulativo. Para Whitehead, o "Homem" não é a medida de todas as coisas. Ele é um dos poucos pensadores do século XX que ousam "se aventurar para além da esfera humana" (Harman 2011, 190) e coloca todas as entidades em pé de igualdade. Whitehead rejeita a ideia de que o abismo entre o humano e o mundo é o mais importante. Muito pelo contrário. Para o filósofo, todas as entidades atuais no universo estão em pé de igualdade ontológica. Como o próprio Whitehead explica, nenhum privilégio ontológico especial pode distinguir Deus do "sopro mais trivial da existência no distante espaço vazio", apesar de todas as "gradações de importância e diversidade de função (...), todos estão no mesmo nível" $(1978,18)$. E o que vale para Deus também pode ser dito sobre a subjetividade humana. O que ele prevê, portanto, é um mundo em que todas as coisas percebem umas as outras, em vez de apenas serem percebidas por nós. Steven Shaviro, um dos mais interessantes comentadores da obra de Whitehead, resume:

Interações causais e perceptivas não são mais reféns de categorias centradas no humano. Para Whitehead e Harman, não há hierarquia no que concerne ao ser. Nenhuma entidade - nem mesmo o sujeito humano - pode reivindicar uma primazia metafísica ou servir como um mediador privilegiado. Todas as entidades, de todos os tamanhos e escalas, têm o mesmo grau de realidade. Todos elas interagem umas com as outras da mesma forma, e todas elas exibem os mesmos tipos de propriedades. (Shaviro 2014, 34)

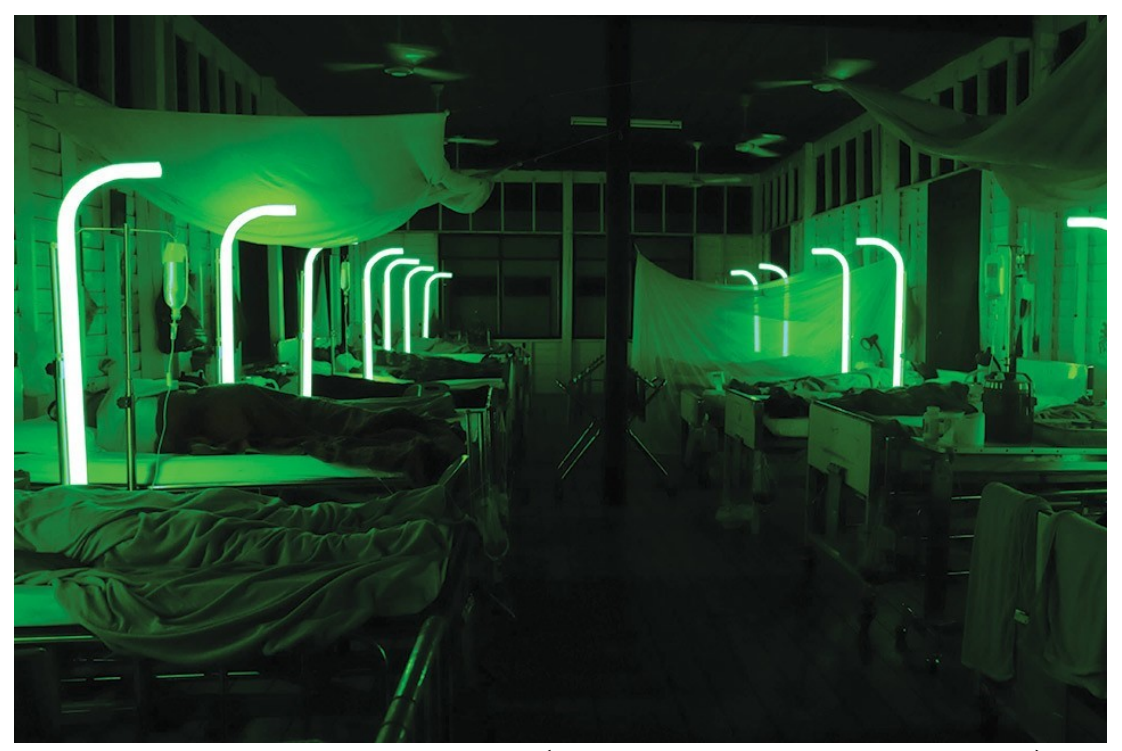

Imagem 2: Cemitério do esplendor (Apichatpong Weerasethakul, 2015) (C) Kick the Machine 
O objetivo fundamental da filosofia de Whitehead é sempre o de superar o que ele mesmo chamou de "bifurcação da natureza", ou divisão absoluta entre "a natureza apreendida na consciência e a natureza que é causa da consciência” (1994, 30-31). De um lado, há a aparência fenomênica do mundo para nós: "o verde das árvores, o canto dos pássaros, o calor do sol, a dureza das cadeiras, e a sensação do veludo" (Whitehead 1994, 31). Do outro, há a realidade física oculta: "o sistema de conjectura de moléculas e elétrons que tanto afeta a mente a produzir a consciência da aparente natureza" (Whitehead 1994, 31). O pensamento moderno é amplamente fundado sobre essa bifurcação (qualidades primárias e secundárias, noumena e phenomena, "a imagem manifesta" e "a imagem científica”, etc.). Whitehead deseja superá-la em absoluto.

Não podemos empreender uma seleção rigorosa. Para nós, o fulgor avermelhado do poente deve ser parte tão integrante da natureza quanto o são as moléculas e as ondas elétricas por intermédio das quais os homens da ciência explicariam o fenômeno. Cabe à filosofia natural analisar como esses diferentes elementos da natureza se interligam. Ao fazer essa exigência, julgo-me adotando nossa atitude instintiva imediata para com o conhecimento perceptual, que somente e abandonado sob influencia da teoria. (Whitehead 1994, 37)

O desejo de Whitehead de acabar com a bifurcação da natureza o fez mergulhar em um longo processo de especulação metafísica. No final, em obras como Process and Reality e Adventures of Ideas, ele delineia uma visão de âmbito cosmológico. Para Whitehead, o ser de uma coisa é constituído por seu devir. Na verdade, se quisermos ser rigorosos, não há coisas. O mundo é feito de processos. E cada coisa deve primeiro tornar-se o que é. Nada é dado previamente. Noções como "tornar-se" e "criatividade" são bastante genéricas. Não se relacionam com seres humanos em particular; podem referir-se a todos os acontecimentos no cosmos. Existem, naturalmente, diferenças de grau. Em Process and Reality, Whitehead alerta pelo menos duas vezes que o ser humano apresenta uma originalidade maior do que o de uma pedra. No entanto, essas diferenças de grau nunca são convertidas em diferenças de gênero. Todas as coisas são ativas e transformadoras. Desta forma, Whitehead mina o antropocentrismo inveterado da filosofia ocidental e engloba ambos os lados da bifurcação da natureza. Eu não sou um sujeito diante de um mundo que está fora de mim, porque sujeito e objeto "são eles próprios processos de tornar-se, e todas as coisas reais são igualmente objetos [e] sujeitos" (Whitehead 1978, 56-57).

A filosofia ocidental é centrada em questões de cognição. Privilegia a epistemologia (como podemos saber o que sabemos?) em detrimento da ontologia (o que é o ser?). Whitehead, pelo contrário, insiste que o mundo não pode estar dependente de nosso conhecimento dele, que não se deve subordinar o que é conhecido à nossa maneira de saber. Na verdade, a nossa maneira de saber é por si só 
uma consequência ou um produto, de como as coisas realmente são e do que fazem.

De acordo com esse ponto de vista, as coisas experimentadas devem ser distintas da noção que temos delas. Até o ponto em que há dependência, as coisas abrem o caminho para a cognição, e não vice-versa. Mas o ponto é que as verdadeiras coisas experimentadas entram em um mundo comum que transcende o conhecimento, embora o inclua. (Whitehead 2006, 115)

Para Whitehead, ecoando William James, e em afinidade absoluta com a experiência de se ver um filme como Cemitério do esplendor, "encontramo-nos em um mundo vibrante, em meio a uma democracia de criaturas" (1978, 50). Experimentamos nossos seres finitos e sentidos físicos na presença de um universo cujas possibilidades são infinitas, e, mesmo que não possamos apreendê-las, essas infinitas possibilidades estão lá, como realidades possíveis. Somos levados a crer, de uma forma bastante serena, que a matéria não é inerte e passiva, mas imanentemente ativa, produtiva e formativa. Eu não venho a conhecer um mundo de coisas fora de mim. Sinto-me, juntamente com as coisas que vão além do meu conhecimento delas, que somos todos iguais, habitantes de um "mundo comum".

Apichatpong Weerasethakul, por sua vez, descreve seu trabalho como um "cinema aberto": "Às vezes você não precisa entender tudo para apreciar uma certa beleza" (Rose 2010), diz ele. "E acho que o cinema funciona da mesma maneira. É como entrar na mente de alguém. O padrão de pensamento é bastante aleatório, saltando aqui e ali como um macaco" (Rose 2010). Ora, o que significaria pensar como um macaco saltando aqui e ali? Esta é a deliciosa pergunta que o cinema de Apichatpong Weerasethakul, em uma afinidade curiosa com o pensamento de Whitehead, nos propõe investigar, em um gesto especulativo que toca os limites daquilo a imagem pode fazer. Apichatpong Weerasethakul e Whitehead nos levam a esta encruzilhada entre forças e formas de pensamento, nos instigam a investigar, em um processo sempre em curso, como este limiar carrega uma forma incipiente, desde a imagem até a experiência, da experiência à imagem.

Pensar com Whitehead e Apichatpong Weerasethakul significa aceitar uma aventura a partir da qual nenhuma das palavras que nos servem como pontos de referência poderá sair ilesa e intocada, mas da qual nenhuma delas será desclassificada ou denunciada como um vetor de ilusão. Todas as palavras, conceitos e teorias são parte do problema, se se referem aos porquês da experiência humana ou para os comos da "realidade objetiva". Isto porque, em geral, tentam contornar o problema em vez de elevá-lo; ou seja, tentam atenuar as contradições e tornar compatível o que se define como conflituoso. Whitehead sugere que a filosofia começa e termina no maravilhamento, na fascinação. Poderíamos dizer a mesma coisa sobre qualquer abordagem crítica ou teórica em relação ao cinema. Seu 
objetivo não deve ser o de deduzir e impor normas cognitivas ou conceitos epistemológicos a respeito daquilo que o cinema é ou deveria ser, mas sim nos tornar mais plenamente conscientes de como a realidade e o cinema sempre escapam e perturbam essas normas e conceitos.

O mundo e o cinema existem, portanto, no modo interrogativo. Pensar com Apichatpong Weerasethakul e Whitehead é invariavelmente se entregar a uma abordagem ontológica do cinema em uma interrogação interminável, em uma dialética sem síntese. Isso é, na verdade, o que Whitehead - assim como, é preciso dizer, Merleau-Ponty - pensava ser a própria natureza da filosofia: a interrogação de sua própria possibilidade. Com a ajuda de Apichatpong Weerasethakul e de Whitehead podemos elaborar uma abordagem ontológica do cinema que desafie todas as dicotomias e nos leve a uma experiência singular de desorientação no coração das experiências mais familiares. É uma empreitada meticulosa, grave, e sempre a ser retomada: o cinema como uma arte ontológica, como a arte de quebrar dualismos.

Cemitério do esplendor é o fundador da sua própria realidade. Não reconhece nenhuma divisão primordial, mas uma continuidade conflituosa. Como bem descreve Erin Manning (Bordeleau, Pape, Rose-Antoinette, Szymanski 2017, 16), os filmes de Apichatpong Weerasethakul nos tornam visionários, e, ao fazê-lo, exigem de nós um pensamento que não recue diante dessa experiência incerta e ambivalente que nos liga, esteticamente, emocionalmente, sensualmente, com o mundo, que nos faz conviver não apenas com o que vemos ou vimos, mas com o que ainda não conseguimos ver. Convida-nos a ver com outros olhos, para além do que entendemos como real, para lá do humano.

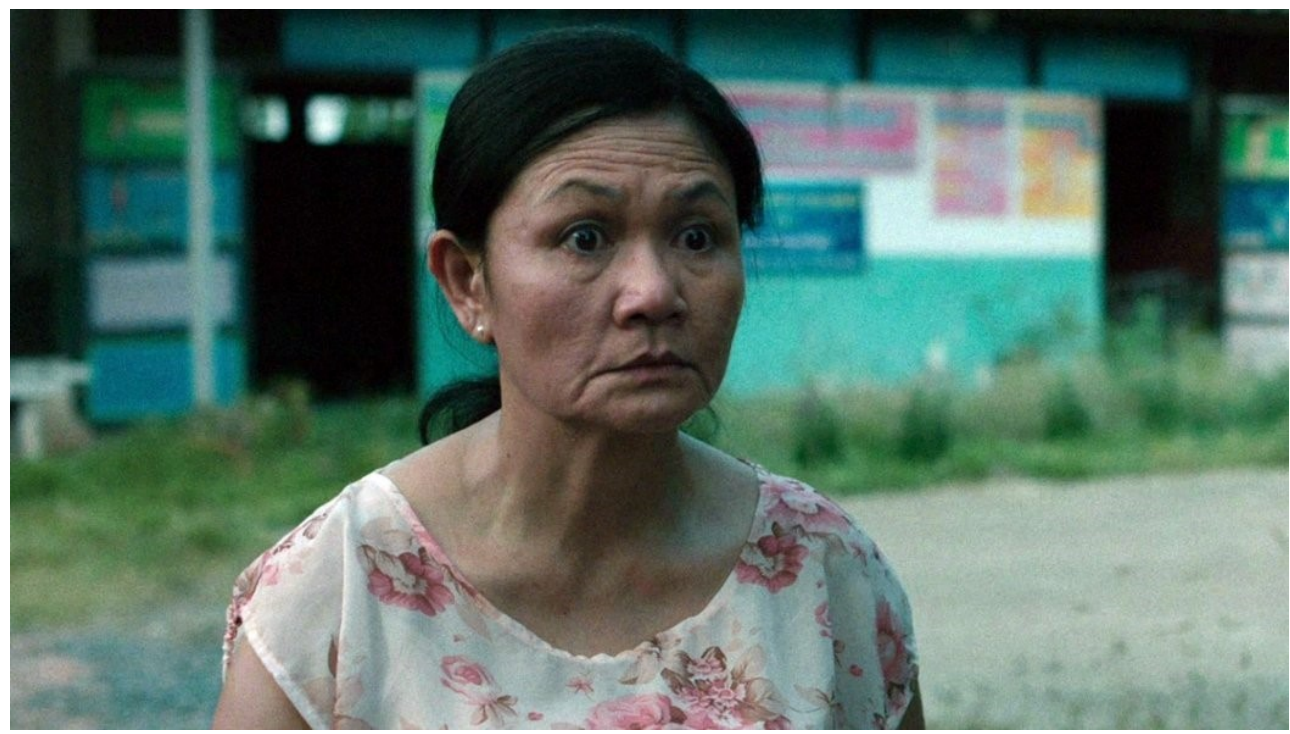

Imagem 3: Cemitério do esplendor (Apichatpong Weerasethakul, 2015) (c) Kick the Machine 
É o que último plano de Cemitério do esplendor sintetiza com muita beleza. Jen está sentada, imóvel, em um banco de praça, com os olhos bem abertos e uma expressão que mistura espanto e êxtase. É um close-up - um dos poucos dedicados a seres humanos. O plano dura alguns minutos. Ela olha para uma máquina de escavação do solo. Ela olha para os meninos que jogam futebol na sua frente. Mas ela vê mais do que isso. Ela sente mais do que isso. Ela percebe mais do que isso. Parece experimentar a existência total e irredutível de todas as coisas. Dá voz a um tipo de conhecimento não-humano, mais antigo do que a própria humanidade, capaz de ver, como se, para além de toda conquista e hipótese, o universo pertencesse ao que é dado.

\section{BIBLIOGRAFIA}

Bordeleau, Érik, Pape, Toni, Rose-Antoinette, Ronald, Szymanski, Adam. 2017. Nocturnal Fabulations - Ecology, Vitality and Opacity in the Cinema of Apichatpong Weerasethakul. Londres: Open Humanities Press.

Bragança, Felipe. 2006. "Seis perguntas para Apichatpong Weerasethakul". Cinética. http://www.revistacinetica.com.br/entrevistajoe.htm

Dalí, Salvador. 1998. The Collected Writings of Salvador Dalí. Cambridge: Cambridge University Press.

Harman, Graham. 2013. Bells and Whistles: More Speculative Realism. UK: Zero Books.

-_-. 2011. Guerrilla Metaphysics: Phenomenology and the Carpentry of Things. Open Court.

-_- 2009. Prince of Networks: Bruno Latour and Metaphysics. Melbourne: re.press.

- - - 2010. "I am also of the opinion that materialism must be destroyed." Society and Space 28, 5: 772-790.

Koresky, Michael. 2016. "This World and the Last". Reverse Shot. http://reverseshot.org/reviews/entry/2094/cemetery_of_sp lendor

Quandt, James. 2009. "Resistant to Bliss: Describing Apichatpong". In Apichatpong Weerasethakul, ed. James Quandt, 13-30. Vienna: Synema.

Meillassoux, Quentin. 2008. After Finitude: An Essay on the Necessity of Contingency. London: Bloomsbury Academic. 
Merleau-Ponty, Maurice. 1994. Fenomenologia da percepção. São Paulo: Martins Fontes.

-_- 1991. Sense and Non-Sense. Evanston, Illinois: Northwestern University Press.

———. 2000. O visível e o invisível. São Paulo: Perspectiva.

Rayn, Tony. 2009. "Touching the Voidness". In Apichatpong Weerasethakul, ed. James Quandt, 132-142. Vienna: Synema.

Rithdee, Kong. 2015. "Cemetery of Splendour". Cinema Scope 63, 48.

Rose, Steve. 2010. “You Don't Have to Understand Everything': Apichatpong Weerasethakul". The Guardian, 11 de novembro. https://www.theguardian.com/film/2010/nov/11/apichatpo ng-weerasethakul-director-uncle-boonmee-interview

Shaviro, Steven. 2014. The Universe of Things: On Speculative Realism. Minneapolis, MN: University of Minnesota Press.

Sparrow, Tom. 2014. The End of Phenomenology: Metaphysics and the New Realism. Edinburgh: Edinburgh University Press.

Stengers, Isabelle. 2014. Thinking with Whitehead: A Free and Wild Creation of Concepts. Cambridge, MA: Harvard University Press.

Whitehead, Alfred North. 1967. Adventures of Ideas. New York: The Free Press.

———. 1994. O conceito de natureza. São Paulo: Martins Fontes.

-_- 1978. Process and Reality. New York: Free Press.

—_—. 2006. A ciência e o mundo moderno. São Paulo: Paulus.

——_. 1927. Symbolism: Its Meaning and Effect. New York: Fordham UP.

\section{FILMOGRAFIA}

Misterioso objeto ao meio-dia (Dokfa nai meuman). [longa-metragem, cores, $35 \mathrm{~mm}$ ]. Dir. Apichatpong Weerasethakul. Kick the Machine. Tailândia, 2000. 83 min.

Eternamente sua (Sud sanaeha). [longa-metragem, cores, 35mm]. Dir. Apichatpong Weerasethakul. Kick the Machine. Tailândia, 2002. $125 \mathrm{~min}$.

Mal dos trópicos (Sud pralad). [longa-metragem, cores, 35mm]. Dir. Apichatpong Weerasethakul. Kick the Machine. Tailândia, 2004. $118 \mathrm{~min}$. 
Síndromes e um século (Sang sattawat). [longa-metragem, cores, $35 \mathrm{~mm}$ ]. Dir. Apichatpong Weerasethakul. Kick the Machine. Tailândia, 2006. 105 min.

Cemitério do esplendor (Rak ti Khon Kaen). [longa-metragem, cores, 35mm]. Dir. Apichatpong Weerasethakul. Kick the Machine. Tailândia, 2015. 122 min.

Recebido em 31-01-2017. Aceite para publicação em 13-07-2017. 